\title{
STOMATAL BEHAVIOR OF DIFFERENT GRAPEVINE CULTIVARS IN RESPONSE TO SOIL WATER STATUS AND AIR WATER VAPOR PRESSURE DEFICIT
}

\author{
J. A. PRIETO ${ }^{1 *}$, É. LEBON ${ }^{2}$ and H. OJEDA ${ }^{3}$ \\ 1: Instituto Nacional de Tecnología Agropecuaria (INTA EEA Mendoza), San Martín 3853, \\ Luján de Cuyo (5507), Mendoza, Argentine \\ 2: INRA Montpellier SupAgro, UMR759 LEPSE, 2 place Viala, 34000 Montpellier, France \\ 3: UE999 Pech Rouge, INRA, 11430 Gruissan, France
}

\begin{abstract}
Aims: Genetic variability in grapevine cultivars may influence their strategy to cope with drought through stomatal regulation of transpiration rate. The aim of the present study was to evaluate the stomatal sensitivity of five cultivars (Ekigaïna, Grenache, Marselan, Mourvèdre, and Syrah) to soil water status and air water vapor pressure deficit (VPD).
\end{abstract}

Methods and results: Leaf gas exchange and canopy light interception efficiency $\left(\varepsilon_{i}\right)$ were evaluated through a wide range of predawn leaf water potential $\left(\psi_{\mathrm{PD}}\right)$ measurements in a field experiment in Southern France. Additionally, greenhouse experiments were carried out to monitor stomatal response to increasing VPD levels. Ekigaïna showed a strong isohydric behavior with the highest decrease in leaf gas exchange in response to soil water stress and VPD. Mourvèdre and Grenache showed a similar but relatively less extreme behavior. These three cultivars showed a constant leaf water status during the day through stomatal regulation and a strong decrease in $\varepsilon_{\mathrm{i}}$. In contrast, Syrah and Marselan displayed anisohydric behavior as they presented a less sensitive stomatal control. Both cultivars showed fluctuating midday leaf water potential and Marselan was the least affected in terms of $\varepsilon_{\mathrm{i}}$.

Conclusion: This study demonstrated that grape cultivars differed in their stomatal response to soil water deficit and VPD. For a given cultivar, a similar stomatal behavior was found in response to both $\psi_{\mathrm{PD}}$ and VPD.

Significance and impact of the results: Adaptation to drought and viticulture viability in hot and dry environments could be achieved by identifying and breeding cultivars with drought tolerance traits.

Key words: anisohydric, genetic variability, isohydric, photosynthesis, VPD, water deficit, water use efficiency

\section{Résumé}

Objectifs : La variabilité génétique existante chez les cépages de vigne peut affecter leur stratégie d'adaptation à la sécheresse en régulant la transpiration au travers de la fermeture des stomates. L'objectif du travail a été d'évaluer la sensibilité des stomates de cinq cultivars (Ekigaïna, Grenache, Marselan, Mourvèdre et Syrah) à la disponibilité en eau du sol et au déficit de pression de vapeur (VPD).

Méthodes et résultats : Les échanges gazeux des feuilles et l'efficience d'interception du rayonnement ( $\varepsilon i$ i) ont été évalués dans une large gamme des valeurs de potentiel hydrique de base $\left(\psi_{\mathrm{PD}}\right)$ en conditions de terrain dans le Sud de la France. En outre, une expérimentation complémentaire en serre a été réalisée pour analyser la réponse des stomates face à une augmentation du VPD. L'Ekigaina a présenté un caractère ioshydrique très marqué avec la plus grande diminution des échanges gazeux en réponse au déficit hydrique du sol et au VPD. Le Mourvèdre et le Grenache ont présenté un comportement similaire bien que moins extrême que l'Ekigaïna. Ces trois cultivars ont montré un potentiel hydrique foliaire constant pendant la journée à cause d'une forte régulation stomatique et une diminution de $\varepsilon_{i}$. Par contre, le Syrah et le Marselan, ont montré un comportement anisohydrique avec un control stomatique moins sensible. Les deux cultivars ont présenté une diminution du potentiel hydrique foliaire à midi tandis que le Marselan a été le moins affecté en termes de $\varepsilon_{\mathrm{i}}$.

Conclusions : La présente étude montre que les cultivars présentent des différences dans leur réponse au déficit hydrique du sol et au VPD. Pour un cultivar donné, un comportement stomatique similaire a été observé en réponse au $\psi_{\mathrm{PD}}$ et au VPD.

Impacts et signification des résultats : L'adaptation à la sécheresse et la viabilité de la viticulture sur de climats chauds et secs pourrait être atteint par la sélection de cultivars avec de caractères de tolérance.

Mots clés : anisohydrique, variabilité génétique, isohydrique, photosynthèse, VPD, déficit hydrique, efficience d'utilisation de l'eau 


\section{INTRODUCTION}

Water is one of the most limiting factors for viticulture in Mediterranean regions (Cifre et al., 2005) where the evaporative demand is elevated during summer and rainfall is scarce (Koundouras et al., 1999). In these regions where drought is frequent during the vegetative cycle, water stress is an important factor that influences vine vigor (Gomez del Campo et al., 2002; Lebon et al., 2006), berry growth (McCarthy 1997 and 2000; Ojeda et al., 2001) and berry composition (Koundouras et al., 1999; Ojeda et al., 2002; Van Leeuwen et al., 2003). This specificity makes the Mediterranean viticulture extremely vulnerable to climate change. The growers are therefore forced to improve plant water use efficiency in anticipation of the effects and especially the consequences of increasing periods of intense drought (Hamdy et al., 2003; Condon et al., 2004; Parry et al., 2005). New strategies for irrigation management have recently been developed to enhance water use efficiency and quality. Partial root drying (PRD) and regulated deficit irrigation (RDI) programs have been proposed as being the most promising tools (Cifre et al., 2005; Chaves et al., 2007). However, as the need for water supply to support non-agricultural activities is expected to increase, the need for water-efficient grapevine varieties becomes increasingly urgent. In this sense, more knowledge on the mechanisms involved in grapevine tolerance to water stress and a better understanding of their genetic variability will be relevant to future breeding programs (Parry et al., 2005).

To counter the effect of soil water deficit and VPD, plants control their transpiration rate by regulating stomatal aperture, which reduces fluctuations in the water status of tissues and maintains xylem integrity (Jones, 1998). Many studies on diurnal and seasonal monitoring of plant water potential have indicated a substantial range in the capacity of plants to maintain the water status of tissues (Franks et al., 2007). Based on their stomatal control behavior under fluctuating environmental conditions, plants have been classified in two categories: isohydric and anisohydric. Isohydric plants maintain a tight stomatal regulation of transpiration rate which results in the maintenance of a nearly constant leaf water potential in drought-exposed and well-irrigated plants (Tardieu and Simonneau, 1998). In contrast, anisohydric plants display a lower stomatal control of transpiration rate which results in large fluctuations in leaf water potential under soil water deficit and evaporative demand. Two components have been shown to be involved in the stomatal control of transpiration rate: a sensitivity to transpiration rate itself in response to short-term variations in leaf water balance (Mott and Parkhurst, 1991; Mott and Franks, 2001; Buckley, 2005) and a sensitivity to decreasing soil water potential induced by root signals (Davies and Zhang, 1991; Tardieu and Davies, 1992; Davies et al., 2002). The way these two components are integrated seems to differ between isohydric and anisohydric plants. It has been suggested that stomatal control in isohydric species is linked to an interaction between hydraulic and rootmediated hormonal information, while stomatal closure in anisohydric species responds preferentially to root signals (Tardieu and Simonneau, 1998).

The ecological advantages of isohydry, which is prevalent in tree species growing in environments with highly fluctuating evaporative demand and soil water status, are readily apparent as xylem integrity is preserved. On the other hand, the advantages of anisohydry, mostly prevalent in herbaceous species, are less apparent because of the higher likelihood of xylem embolisms (Franks et al., 2007). However this mode of operation seems more favorable to high gas exchange and assimilation rates.

Although considered drought-resistant, variation in drought tolerance exists among Vitis sp. (Carbonneau, 1980) and within Vitis vinifera cultivars (Chaves et al., 1987; Bota et al., 2001). This variability is mainly explained at the leaf scale by differences in stomatal behavior (Carbonneau, 1980; Winkel and Rambal, 1990; Albuquerque Regina, 1993, Schultz, 1996; Medrano et al., 2003).

The intraspecific variability of stomatal behavior was first demonstrated by Schultz (1996 and 2003) within two grape cultivars (Grenache and Syrah) of Vitis vinifera. Grenache, of Mediterranean origin and reputed to be very resistant to drought, displayed isohydric behavior and was classified as drought-avoiding. Meanwhile, Syrah, of mesoic origin from North Rhone Valley, displayed anisohydric behavior and was classified as droughttolerant. Under high evaporative demand and soil water deficit, Syrah which did not control water status achieved crop maturation whereas Grenache which strongly regulated it failed to mature crop. These results were surprising as they contrast with the respective growth habits of these varieties. Until now, there was no clear picture of the relationship between drought tolerance and stomatal behavior in grapevine cultivars.

In this report we have studied the stomatal behavior of five grape cultivars with contrasting drought tolerance: Ekigaïna, Grenache, Marselan, Mourvèdre, and Syrah. The objectives of this study were (i) to characterise the dynamic responses of leaf water potential and leaf gas exchange under increasing drought in field conditions and (ii) to analyse specifically the stomatal response to VPD under controlled environments (greenhouse experiments). From an agronomical point of view, the hypothesis is that drought adaptation results from the ability of the grapevine cultivar to reduce gas exchange gradually in response to increasing drought, thus maintaining a significant assimilation rate under high soil 
water deficit and high evaporative demand (i.e. anisohydric behavior).

\section{MATERIALS AND METHODS}

\section{Field experiments}

a) Experimental design and plant material

Experiments were carried out in 2004 and 2005 in the south of France at the INRA's Experimental Unit of Pech Rouge, Gruissan, France ( $\left.43^{\circ} 10^{\prime} \mathrm{N}, 3^{\circ} 06^{\prime} \mathrm{E}\right)$. The climate is Mediterranean with dry and hot summers. The soil characterised by a high proportion of calcareous stones was classified as a perrosol (FAO-UNESCO, 1981). Five grapevine cultivars were studied: three traditional varieties of the region (Syrah, Grenache and Mourvèdre) and two varieties from INRA's breeding programs [Ekigaïna (Tannat x Cabernet Sauvignon) and Marselan (Cabernet Sauvignon $x$ Grenache)]. The study was conducted in two vineyards which are $400 \mathrm{~m}$ away from each other. In the first vineyard, Marselan, Ekigaina, Syrah and Grenache grafted on 140Ru rootstock were planted in SE-NW rows in 1993. The vine spacing was $2.50 \mathrm{x} 1 \mathrm{~m}$ and vines were bilateral spur pruned and trained to a VSP system. In the second vineyard, Mourvèdre (synonym of Monastrell) grafted on 140Ru was planted in 1990 and cultivated following the same practises expected for SW-NE row orientation.

\section{b) Soil water availability}

For each cultivar, three homogeneous plots of 30 vines distributed in five rows and with contrasting soil water availability were identified. Plots were annotated hereafter as WS1, WS2, and WS3 for high, moderate, and low soil water availability, respectively. These differences in soil water availability were caused by differences in soil depth as a consequence of the vineyard slope. The plots location was based on previous estimations of spatial distribution of soil water availability determined by predawn leaf water potential measurements during the 2004 growing season and the individual vine vigor measured by trunk circumference.

During the 2005 growing season, the WS2 and WS3 plots were only rainfed. By contrast, additional irrigation was applied five times $(5 \times 15 \mathrm{~mm})$ to WS1 to maintain water deficit differences between plots.

\section{c) Leaf water potential measurements}

Predawn leaf water potential $\left(\psi_{\mathrm{PD}}\right)$ was measured between 0400 and 0500 (GMT, Greenwich Mean Time) with a pressure chamber (Soil Moisture Equipment Corp., Santa Barbara, USA). Measurements were performed on 10 leaves in each subfield at 5 time points during the growing season. Midday leaf water potential $(\psi l)$ was measured at 1300 (GMT) on the same day and on the same plants as for $\psi_{\mathrm{PD}}$.

\section{d) Leaf gas exchange measurements}

Leaf gas exchange was measured under saturating sunlight (PPFD $>800 \mu \mathrm{mol} \mathrm{m}^{-2} \mathrm{~s}^{-1}$ ) with a portable gas exchange equipment (ADC Lcpro, BioScientific Ltd, Hoddesdon, Herts, UK) equipped with a Parkinson leaf chamber. Measurements were performed during sunny days on the same vines as for $\psi_{\mathrm{PD}}$ and $\psi_{1}$ measurements. To evaluate the daily maximal photosynthesis $\left(\mathrm{Pn}_{\max }\right)$ and maximal stomatal conductance $\left(\mathrm{gs}_{\max }\right)$, measurements were taken twice a day, between 1000 and 1130 (GMT) and between 1300 and 1430 (GMT), and on five leaves in each subfield (corresponding to 15 leaves per cultivar). As five cultivars were analysed, the time between the first and the last leaf measurement was approximately 1 hour. This sampling method was chosen to avoid varying environmental conditions during measurements. As $\psi_{\mathrm{PD}}$ and $\psi_{1}$ were performed on the same vine, only 15 leaves per cultivar were used at each sampling date to avoid vines defoliation.

Cultivar-specific stomatal sensitivity was analysed using the Ball, Woodrow and Berry (BWB) model which allows the evaluation of gs response to the combined effects of climate variables through the stomatal sensitivity factor $(k)$ (Ball et al., 1987). This factor is calculated as the slope of the linear relationship between gs and the composite factor $\mathrm{Pn} *[\mathrm{HR} / \mathrm{Ca}]$ where $\mathrm{HR}$ is relative humidity and $\mathrm{Ca}$ is the $\mathrm{CO}_{2}$ concentration at the leaf surface. As this factor varies during the season and with water status, $k$ was calculated separately for each day of measurement and was plotted against predawn leaf water potential (Schultz et al., 1999).

\section{d) Canopy light interception efficiency $\left(\varepsilon_{\mathbf{i}}\right)$}

Canopy light interception efficiency (ci) was calculated as the fraction of the incoming global solar radiation intercepted by a plant canopy over a defined period of time. In 2005, this coefficient was estimated four times for each cultivar and subfield, and the measurements were carried out during the growing season between full bloom and harvest (stages 23, 31, 35, and 38 of the modified E-L scale; Coombe 1995) using an hemispherical photography method (Louarn et al., 2005). For each plot, 36 hemispherical photographs distributed in two positions (row, mid-interrow) x 18 repeated transects were taken (Nikon coolpix 950 digital camera equipped with FC-E8 Nikon Fisheye converter). Pictures were taken just before sunrise with no direct incoming light illuminating the canopy or during cloudy days. Image analysis was performed using GLA software (Gap Light Analyzer version 2.0, SFU, Burnaby, British Columbia, Canada). 
The cumulative radiation intercepted by the canopy and the average ci over the period between full bloom and harvest (stages 23-38) for each subfield were estimated by interpolating zi measured between each date.

\section{d) Meteorological data and climate indexes}

Standard meteorological data were obtained from a weather station (Agroclim, INRA network) located at the Experimental Unit at approximately $600 \mathrm{~m}$ from the experiment site. Standard climatic indexes for grapevine (heliothermal, dryness and cool night indexes) were calculated according to Tonietto and Carbonneau (2004).

\section{Greenhouse experiments}

a) Experimental design and plant material

To characterise the gs response to changes in VPD, an experiment was carried out in a greenhouse during the spring of 2005 at the Campus SupAgro - INRA, Montpellier, France ( $43^{\circ} 38^{\prime}$ N, $3^{\circ} 53^{\prime}$ E). One-year-old cuttings from Ekigaïna, Mourvèdre, Syrah, and Marselan were rooted and grown in $3.8 \mathrm{~L}$ pots filled with a soil mixture composed of $17 \%$ clay, $36 \%$ loam, and $47 \%$ sand. Plants were irrigated in the morning with a Hoagland N/5 nutritive solution approximately deux hours before the beginning of the measurements. For each cultivar, eight homogeneous plants were selected according to leaf area development.

\section{b) Leaf gas exchange measurements}

Gas exchange measurements were done with the same portable equipment as previously described for field experiments. Stomatal conductance response curves to VPD were done by gradually reducing humidity to a preselected set of VPD levels $(1,87 \mathrm{kPa} ; 2,27 \mathrm{kPa}$; $2,67 \mathrm{kPa}$ and 3,07 kPa). At each step of the response curve, VPD was stabilised for 20 minutes to allow stomatal conductance adaptation to the new environmental conditions. Air temperature, photosynthetic photon flux density (PPFD) and $\mathrm{CO}_{2}$ concentration were automatically controlled at $25^{\circ} \mathrm{C}, 1500 \mu \mathrm{mol} \mathrm{m}{ }^{-2} \mathrm{~s}^{-1}$, and $360 \mathrm{ppm}$, respectively. The plants were maintained at saturating light conditions $\left(>1200 \mu \mathrm{mol} \mathrm{m}^{-2} \mathrm{~s}^{-1}\right)$ during measurement to avoid differences in illumination between the leaf being measured and the rest of the plant. Response curves were replicated on eight plants per cultivar.

c) Statistical analysis

The STATGRAPHICS Plus v.4 software (StatPoint Inc., Northern Virginia, USA) was used to compare differences between the means by Duncan's test. Nonlinear adjustments were fitted following an exponential function with two and three parameters estimated by TableCurve 2D v.2.03 (Jandel Scientific, San Rafael, USA). All cultivars were forced to the same fitting to compare genotype responses. As the fitting was the same for all cultivars, the statistical analysis allowed the comparison of the parameters of the whole response curve. Differences in adjustments between data sets were tested by comparing $\Sigma \mathrm{Ssi}$ (sum of the residual sums of squares for individual fits to each data set) with SSc (residual sum of squares for the common fit to the whole data set) using the statistic

$$
\mathrm{F}=\frac{\operatorname{SSc}-\sum_{i=1}^{n} \mathrm{SSi} /((\mathrm{n}-1) \cdot \mathrm{k})}{\sum_{i=1}^{n} \mathrm{SSi} /\left(\mathrm{N}_{\text {data }}-\mathrm{k}\right)}
$$

which follows Fisher's law with (n-1)k and (Ndata-k) freedom degrees. Ndata is the total number of measured points, $n$ is the number of individual regressions and $\mathrm{k}$ is the number of parameters fitted in each regression.

\section{RESULTS}

\section{Field experiments}

\section{a) Climate}

During 2004, rainfalls were mostly distributed at the beginning of spring and at the end of summer, with a cumulative rainfall during the growing season around $411 \mathrm{~mm}$ (Figure 1). During the 2005 season, the water deficit was higher (the cumulative rainfall was about 387 $\mathrm{mm}$ ) mainly because of the scarcity of precipitations during spring and a major part of summer. Cumulative

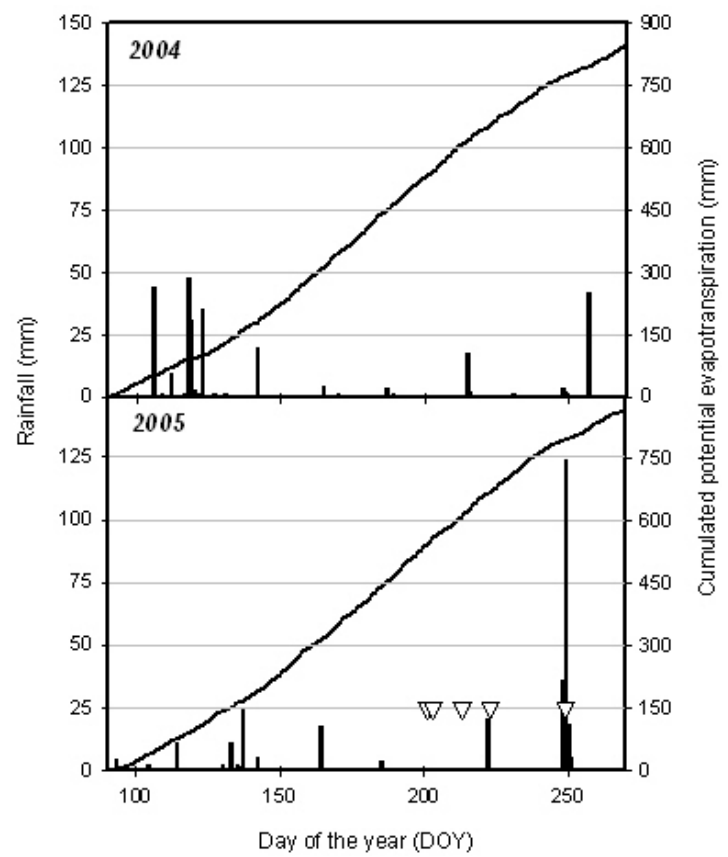

Figure 1. Cumulative Penman-Monteith potential evapotranspiration (solid line) and rainfall (vertical bars) during years 2004 and 2005 in Pech Rouge, France. Arrows indicate irrigation dates in 2005. 
potential evapotranspiration was around $900 \mathrm{~mm}$ and mean summer temperature was about $25^{\circ} \mathrm{C}$ for both years. According to the multicriterion climatic classification (Tonietto and Carbonneau, 2004), both years were classified as moderately dry with a temperate/warm climate and a night cold index around $15.7^{\circ} \mathrm{C}$.

b) Seasonal patterns of soil water deficit

The evolution of predawn leaf water potential $\left(\psi_{\mathrm{PD}}\right)$ for both seasons reflects the specific climatic conditions of each year (Figure 2). Predawn leaf water potential decreased earlier during the 2005 growing season (approximated from full bloom, DOY 160) than the 2004 growing season (approximated from one month after full bloom, DOY 190), and reached its lowest values in 2005 at veraison and at harvest in 2004 . At this time, the maximal range of water deficit was about -0.4 to -1.0 MPa for WS1 and WS3 plots, respectively, and was similar in both years.

\section{Day of the year (DOY)}

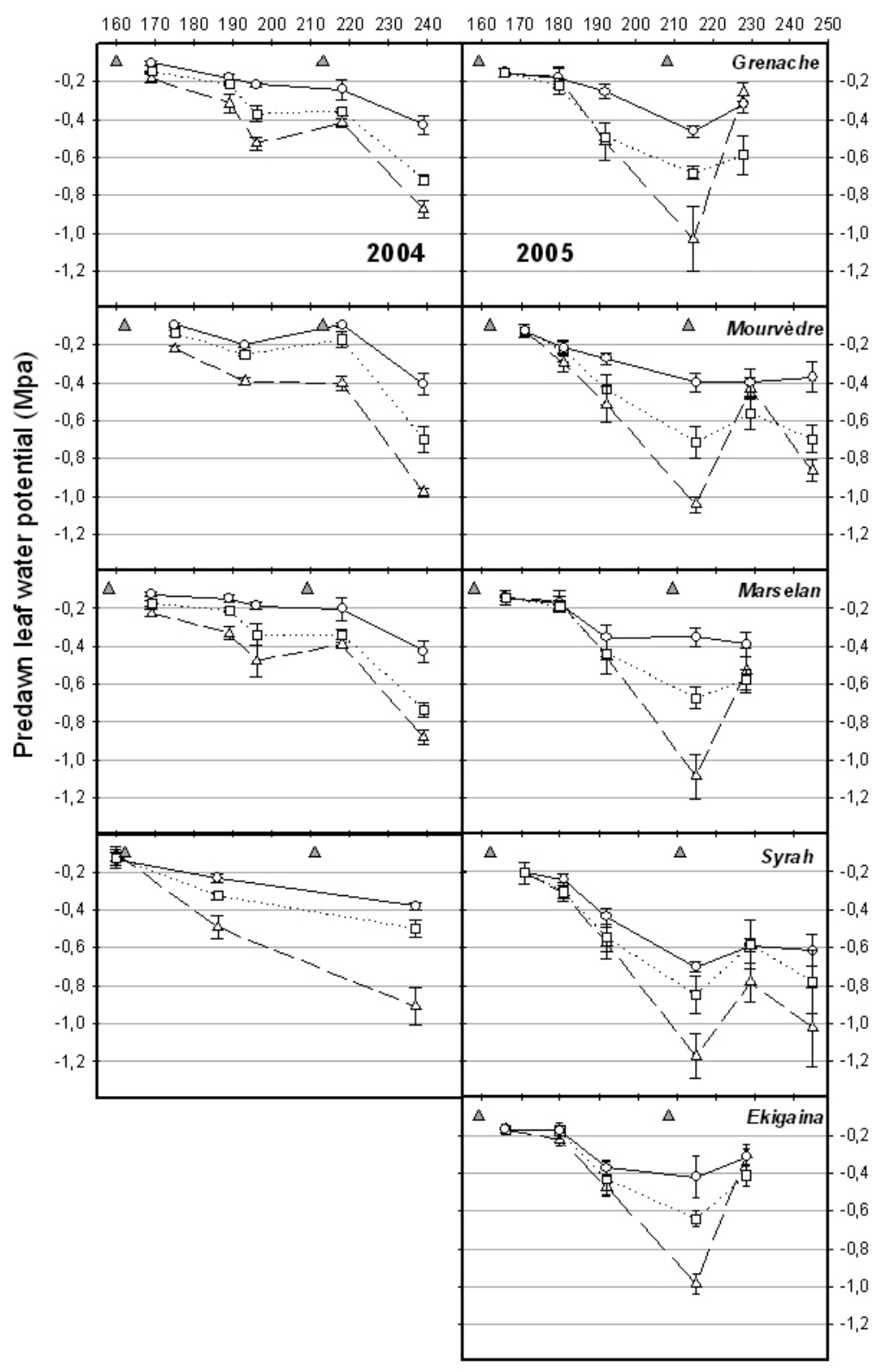

Figure 2. Time course of predawn leaf water potential ( $\psi$ PD) during growing seasons 2004 and 2005 for grapevine cultivars Grenache, Marselan, Mourvèdre, Syrah and Ekigaïna on the three subfields WS1(circle); WS2 (square); WS3 (triangle).

Values are means of 10 plants \pm confidence intervals at $\mathrm{P}=0.05$. Arrows indicate bloom and veraison (stages 23 and 35 ). 


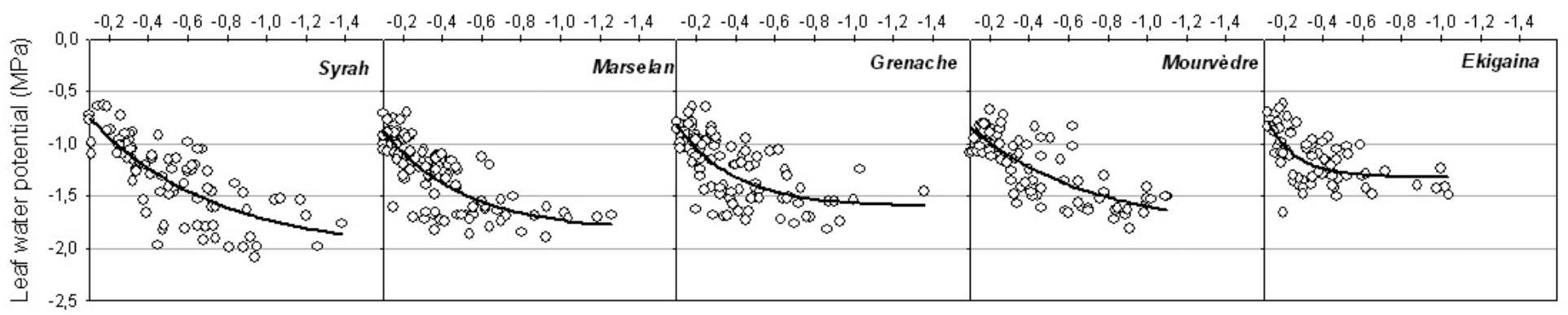

Figure 3. Relationship between predawn leaf water potential $(\psi P D)$ and midday leaf water potential $(\psi l)$ during growing seasons 2004 and 2005 for grapevine cultivars Grenache, Marselan, Mourvèdre, Syrah and Ekigaïna.

Midday leaf water potential $\left[\psi \mathrm{l}=\mathrm{a}+\mathrm{b} \exp \left(-\psi_{\mathrm{PD}} / \mathrm{c}\right)\right]$. For Grenache; a: -1.601 ; b: 1.097; c: -0.296 ; Mourvèdre; a: -1.803 ; b: 1.145; c: -0.587 ; Marselan; a: -1.826; b: 1.224; -0.402; Syrah; a: -2.025; b: 1.495; c: -0.627; Ekigaïna; a: -1.315; b: 1.169; c: -0.151. Pech Rouge, France. 2004 and 2005 .

Table 1. Regression results for stomatal conductance $\left(g_{S}\right)$, photosynthesis $\left(\mathbf{P}_{n}\right)$, intrinsic water use efficiency $\left(W E_{i}\right)$ and stomatal sensitivity factor $(k)$. F values obtained with statistical analyses (see Materials and methods) for each cultivar comparison.

\begin{tabular}{|c|c|c|c|c|c|c|c|c|c|c|c|c|c|c|c|c|}
\hline & \multicolumn{4}{|c|}{ Syrah } & \multicolumn{4}{|c|}{ Mourvèdre } & \multicolumn{4}{|c|}{ Marselan } & \multicolumn{4}{|c|}{ Grenache } \\
\hline & gs & Pn & WUE $_{\mathrm{i}}$ & $k$ & gs & Pn & WUE $_{i}$ & $k$ & $\mathrm{gs}$ & $\mathrm{Pn}$ & WUE $_{i}$ & $k$ & gs & Pn & WUE $_{i}$ & $k$ \\
\hline Ekigaïna & $*$ & $*$ & $*$ & $*$ & $*$ & $*$ & $*$ & $*$ & $*$ & $*$ & $*$ & $*$ & $*$ & $*$ & $*$ & $\mathrm{~ns}$ \\
\hline Grenache & $*$ & $*$ & $\mathrm{~ns}$ & $*$ & $*$ & ns & $\mathrm{ns}$ & ns & $*$ & $\mathrm{~ns}$ & ns & $*$ & & & & \\
\hline Marselan & $*$ & $\mathrm{~ns}$ & ns & ns & ns & ns & $\mathrm{ns}$ & $*$ & & & & & & & & \\
\hline Mourvèdre & * & $\mathrm{ns}$ & ns & $*$ & & & & & & & & & & & & \\
\hline
\end{tabular}

* Cultivars fittings are significantly different from each other at a significance level of $95 \%$, except for stomatal sensitivity factor (k) which is at a significance level of $90 \%$. ns: Not significantly different.

Cultivars differed in the relationship between midday $\left(\psi_{1}\right)$ and predawn leaf water potential $\psi_{\mathrm{PD}}$ (Figure 3). Ekigaïna did not show any decrease of $\psi_{1}$ as $\psi_{\mathrm{PD}}$ reached $-0.4 \mathrm{MPa}$, whereas Syrah showed decreased $\psi_{1}$ values in parallel to decreased $\psi_{\mathrm{PD}}$. Marselan behaved similarly to Syrah while Grenache and Mourvèdre showed intermediate behavior although closer to Ekigaïna.

\section{c) Gas exchange}

To evaluate genotypic sensitivity to soil water deficit, stomatal closure and photosynthetic responses were compared using $\psi_{\mathrm{PD}}$ as an environmental variable (Figure 4). Both physiological parameters decreased as the soil water deficit intensified. Stomatal responses to $\psi_{\mathrm{PD}}$ were adjusted following a two-parameter exponential function while photosynthesis fittings were improved when adjusted to a three-parameter exponential function. For stomatal conductance (Figure 4a-e; Table 1), the parameters of the exponential regressions significantly differed among cultivars ( $\mathrm{P} \leq 0.05)$, except for Marselan and Mourvèdre. Ekigaïna showed the highest decrease in stomatal conductance with $\psi_{\mathrm{PD}}$, followed by Grenache. On the contrary, Syrah was less affected while Mourvèdre and Marselan showed intermediate behaviors. Under conditions of high water stress, stomatal conductance in Ekigaïna remained significantly lower than in the other cultivars. The differences in photosynthetic responses (Figure 4f-j) to soil water deficit were consistent with differences in stomatal conductance responses (Table 1, $\mathrm{P}<0.05)$. Ekigaïna displayed the lowest level of net photosynthesis rate regardless of soil water availability.

Intrinsic water use efficiency (WUE, $\mathrm{Pn} / \mathrm{gs}$ ) initially increased until $\psi_{\mathrm{PD}}$ reached approximately -0.6 $\mathrm{MPa}$ and then decreased as water stress increased (Figure 4k-o). WUE $_{i}$ response to $\psi_{\mathrm{PD}}$ was adjusted following a polynomial function. Parameters were not significantly different among cultivars except for Ekigaïna, which displayed a stronger reduction of $\mathrm{WUE}_{\mathrm{i}}$ below a predawn leaf water potential of $-0.6 \mathrm{MPa}$ (Table $1, \mathrm{P} \leq 0.05$ ). 


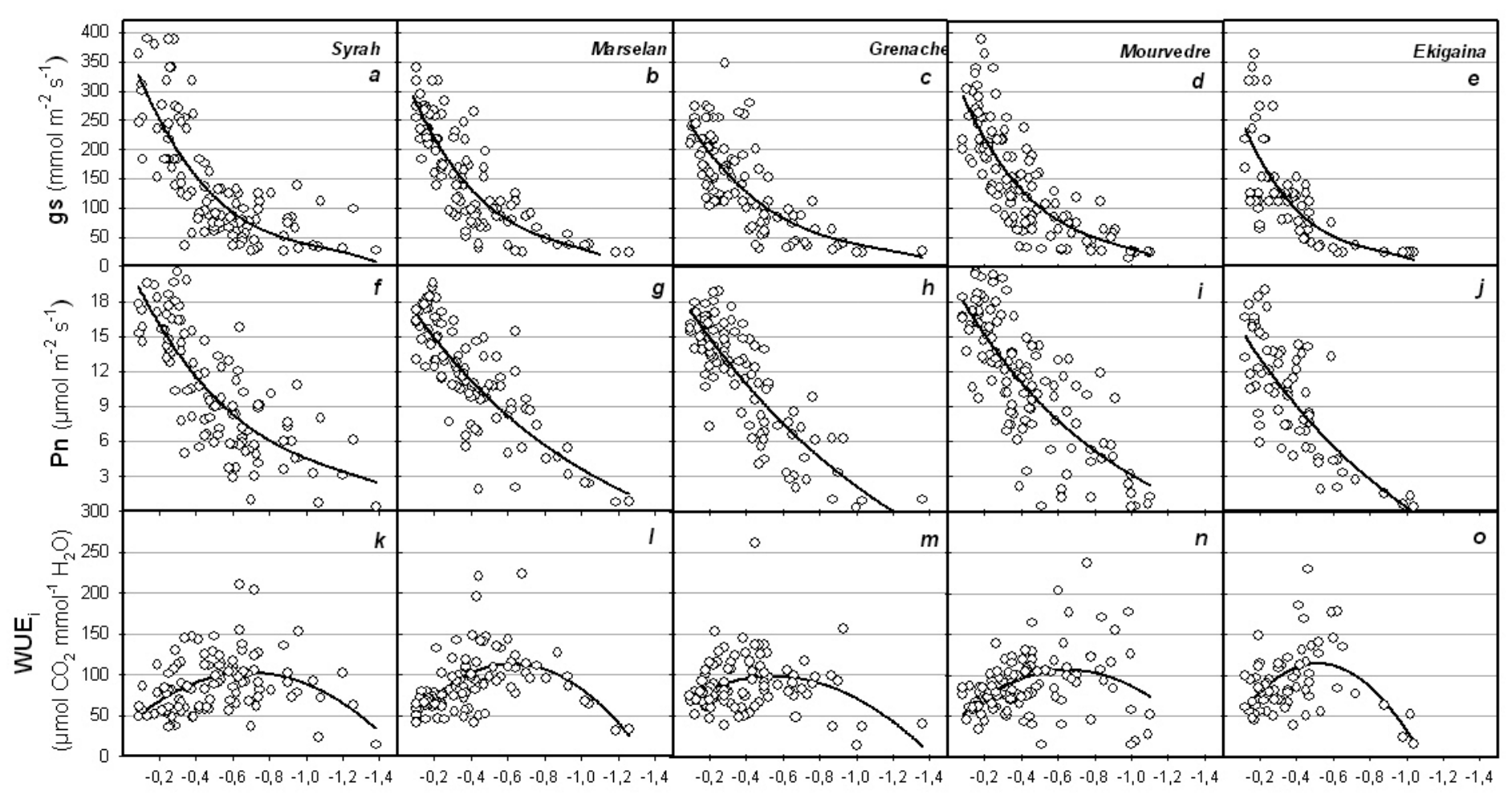

Predawn leaf water potential (MPa)

Figure 4. Stomatal conductance $\left(g_{s}\right)$, net photosynthesis $\left(P_{n}\right)$ and intrinsic water use efficiency $\left(W\right.$ UE $\left.E_{i}\right)$ response to decreasing predawn leaf water potential $(\Psi P D)$ for grapevine cultivars Grenache, Mourvèdre, Marselan, Syrah and Ekigaïna. All years and water treatments confounded.

Stomatal conductance $\left[\mathrm{g}_{\mathrm{s}}=\mathrm{a} \exp \left(-\psi_{\mathrm{PD}} / \mathrm{b}\right)\right]$. For Grenache (a) a: 295.89205; b: -4.733226 ; Mourvèdre (b) a: 361.26548; b: -3.9761563; Marselan (c) a: 364.32666; b: -3.8225046; Syrah (d) a: 411.75686; b: -4.0628484 and Ekigaïna (e) a: 349.86561; b: -3.1269788.

Photosynthesis $\left[\mathrm{Pn}=\mathrm{a}+\mathrm{b} \exp \left(-\psi_{\mathrm{PD}} / \mathrm{c}\right)\right]$. For Grenache (f) a: -12.831836 ; b: 32.318511; c: -13.02595 ; Mourvèdre $(\mathrm{g})$ a: -4.9391291 ; b: 25.22809; c: -8.8030598; Marselan (h) a: -6.1289514; b: 25.416584; -10.466028; Syrah (i) a: 0.62213437; b: 21.746124; c: -5.8008365; Ekigaïna (j) a: -11.497012; b: 29.599311; c: -10.951344.

Intrinsic water use efficiency [WUE $\mathrm{W}_{\mathrm{i}}=\mathrm{a} \psi_{\mathrm{PD}} 2-\mathrm{b} \psi_{\mathrm{PD}}+\mathrm{c}$ ]. For Grenache; $\mathrm{a}:$-1.283; b: 14.012; c: 59.547; Mourvèdre; a: -2.260; b: 26.477; c: 30.734; Marselan; a: -2.169; b: 27.219; c: 27.926; Syrah; a: -1.102; b: 16.544; c: 40.538 and Ekigaïna; a: -3.506; b: 36.295; c: 20.235. Pech Rouge, France. 2004 and 2005.

Figure 5 shows the relationship between the stomatal sensitivity factor $(k)$ and $\psi_{\mathrm{PD}}$ in Syrah and Ekigaïna, a comparison of two extreme cases. Statistical analyses of this factor (Table $1, \mathrm{P} \leq 0.10$ ) permitted us to separate cultivars in two groups: anisohydric behavior (Syrah and Marselan) and a near isohydric behavior (Ekigaïna, Mourvèdre and Grenache).

\section{d) Canopy light interception efficiency}

Light interception efficiency (zi) during the growing season was monitored in 2005 in each subfield. Results showed no differences in maximal capacity of the various cultivars to intercept radiation (Table 2). All cultivars in every water deficit levels (all subfields) reached maximal $\varepsilon i$ at veraison. At this stage, $\varepsilon i$ in WS3 was already lower than in WS1 for all cultivars except Marselan. At the end of the season, the severe water deficit observed in the WS3 subfield induced a higher reduction of $\varepsilon$ i, statistically higher than in moderate (WS2) or low water deficit (WS1) subfields. This reduction in WS3 was maximal for Mourvèdre (29\%) and Ekigaïna (21\%) and minimal for Marselan. On a seasonal basis, the intercepted global radiation estimation for each cultivar suggested that Mourvèdre was less efficient than the other cultivars especially in situation of water deficit (Table 2). By contrast, the capacity of Marselan to intercept radiation was maintained in situation of severe water deficit. The other cultivars displayed intermediate behaviors. The decreasing of $\varepsilon i$ at the end of the cycle in Mourvèdre and Ekigaïna was mainly explained by leaf area reduction as the result of early primary leaf abscission.

\section{Greenhouse experiments}

As VPD increased, relative stomatal conductance $\left(\mathrm{g}_{\mathrm{s}} /\right.$ $\mathrm{g}_{\text {smax }}$ ) displayed a two-stage response (Figure 6). The $\mathrm{g}_{\mathrm{s}} / \mathrm{g}_{\mathrm{smax}}$ first remained steady until VPD reached a 
threshold value of approximately $1.5 \mathrm{kPa}$ then it decreased linearly. A quantification of the variability in stomatal response to VPD was based on comparisons of both the VPD threshold value and the slope of the decreasing portion of the response. Statistical analysis showed that the VPD threshold value was significantly lower $(P<0.001)$ for Marselan $(1.36 \mathrm{kPa})$ than for the other cultivars $(1.76,1.91$ and $1.90 \mathrm{kPa}$ for Syrah, Mourvèdre,

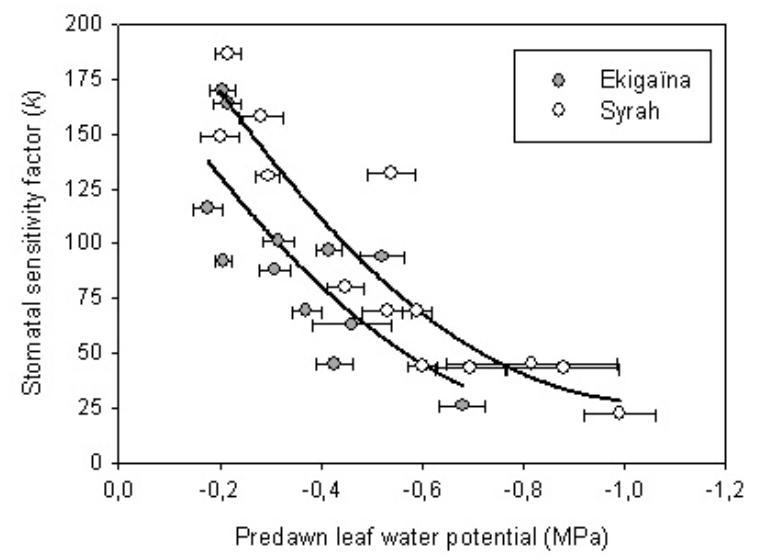

Figure 5. Response of the calculated stomatal sensitivity factor $(k)$ to predawn leaf water potential for grapevine cultivars Syrah and Ekigaïna. Data are means of 10 values \pm confidence interval at $P=0.05$. Pech Rouge, France. 2005. and Ekigaïna, respectively). Furthermore, the absolute value of the slope, which reflected the apparent sensibility of the stomata to the surrounding air water deficit, was significantly higher $(P<0.001)$ for Ekigaïna $(0.39)$ than for the other cultivars $(0.28,0.25$, and 0.22 for Syrah, Marselan and Mourvèdre, respectively).

\section{DISCUSSION}

The dynamic response of leaf water potential and gas exchange parameters to progressive soil drought was studied under field conditions in five grapevine cultivars with contrasting drought tolerance. Three of them are traditionally planted in the French Mediterranean vineyards (Syrah, Grenache and Mourvèdre), whereas the two others have recently been obtained from breeding programs (Marselan, Ekigaïna). From viticultural practices, Mourvèdre has traditionally been identified as putative drought-sensitive, Grenache was generally considered as drought-tolerant, and Syrah as an intermediate tolerant cultivar. The drought tolerance of the Marselan and Ekigaïna cultivars was at this point unknown. Nonetheless, previous field observations indicated a high susceptibility of Ekigaïna to leaf abscission in response to water stress. Overall, these characteristics suggest substantial variability among the cultivars in regulating water status, stomatal conductance, and assimilation under soil water deficit and VPD.

Table 2. Maximal light interception efficiency, final light interception at full maturity (stage 38) and intercepted global radiation over the growing season for the different cultivars during 2005 at the canopy level.

\begin{tabular}{|c|c|c|c|c|c|}
\hline \multirow[b]{2}{*}{ Cultivar } & \multirow[b]{2}{*}{ sub field } & \multicolumn{2}{|c|}{$\varepsilon_{\mathrm{i}}(\%)$} & \multicolumn{2}{|c|}{$\begin{array}{l}\text { Intercepted global } \\
\text { radiation }\end{array}$} \\
\hline & & Maximal & Final & $\mathrm{MJ} \mathrm{m}^{-2}$ & $\begin{array}{l}\% \text { incident } \\
\text { global } \\
\text { radiation }\end{array}$ \\
\hline \multirow{3}{*}{ Ekigaïna } & WS1 & 53.9 & $51.7 a(4 \%)$ & 1166 & 49 \\
\hline & WS2 & 56.0 & $48.0 a(15 \%)$ & 1140 & 47 \\
\hline & WS3 & 49.8 & $39.5 b(21 \%)$ & 999 & 42 \\
\hline \multirow{3}{*}{ Grenache } & WS1 & 55.7 & $53.1 a b(5 \%)$ & 1164 & 49 \\
\hline & WS2 & 56.7 & $56.3 a(0.7 \%)$ & 1223 & 51 \\
\hline & WS3 & 50.0 & $47.7 b(5 \%)$ & 1061 & 44 \\
\hline \multirow{3}{*}{ Marselan } & WS1 & 56.0 & $55.8 a(0.4 \%)$ & 1215 & 51 \\
\hline & WS2 & 59.9 & $52.6 a(12 \%)$ & 1245 & 52 \\
\hline & WS3 & 55.0 & $52.3 a(5 \%)$ & 1185 & 49 \\
\hline \multirow{3}{*}{ Mourvèdre } & WS1 & 52.8 & $47.0 a(11 \%)$ & 1051 & 44 \\
\hline & WS2 & 46.2 & $44.2 a(4 \%)$ & 999 & 42 \\
\hline & WS3 & 48.8 & $34.6 b(29 \%)$ & 915 & 38 \\
\hline \multirow{3}{*}{ Syrah } & WS1 & 54.0 & $51.4 a b(2 \%)$ & 1164 & 49 \\
\hline & WS2 & 53.4 & $52.8 a(1 \%)$ & 1158 & 48 \\
\hline & WS3 & 50.7 & $45.6 b(10 \%)$ & 1043 & 43 \\
\hline
\end{tabular}

Values in brackets indicate the $\%$ of reduction in light interception efficiency at full maturity. Values are means of nine measurements. Statistical analysis is displayed for each cultivar separately. Light interception efficiency values followed by different letters are significantly different at $\mathrm{P} \leq 0.05$ for water deficit subfields within the same cultivar. 


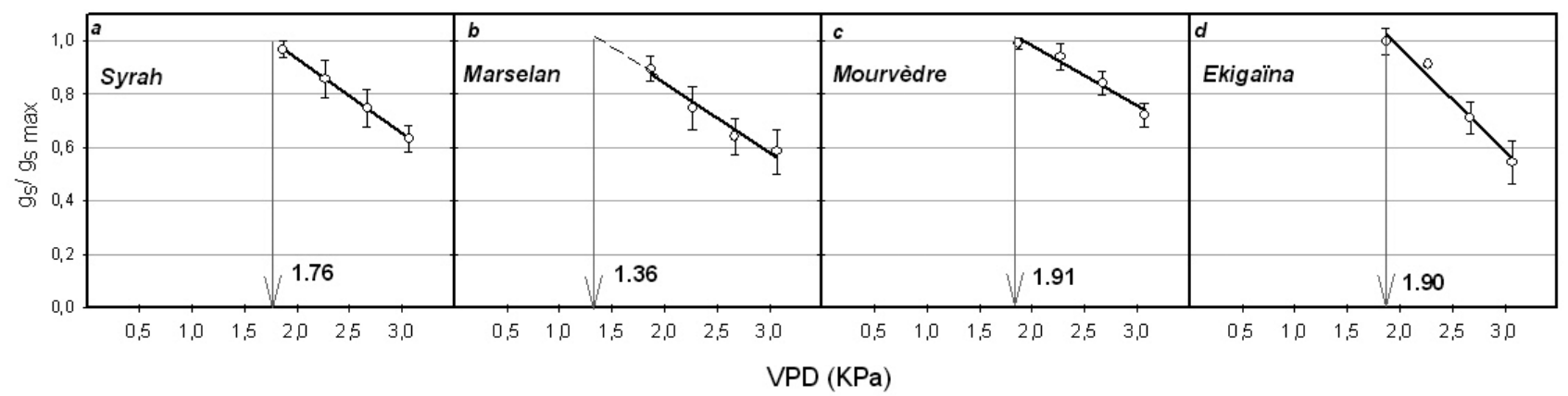

Figure 6. Relationship between stomatal conductance normalized by the maximum stomatal conductance and vapor pressure deficit (VPD) in (a) Syrah

$\mathrm{g}_{\mathrm{s}} / \mathrm{g}_{\mathrm{smax}}=-0,2794 \mathrm{VPD}+1,4915 ; \mathrm{r}^{2}=0.76$, (b) Marselan: $\mathrm{g}_{\mathrm{s}} / \mathrm{g}_{\mathrm{smax}}=-0,2564 \mathrm{VPD}+1,3490 ; \mathrm{r}^{2}=0.57$, (c) Ekigainna: $\mathrm{g}_{\mathrm{s}} / \mathrm{g}_{\mathrm{smax}}=-0,3931 \mathrm{VPD}+$ 1,$7457 ; \mathrm{r}^{2}=0.79$ and (d) Mourvèdre: $\mathrm{gs} / \mathrm{gsmax}=-0,2263 \mathrm{VPD}+1,432 ; \mathrm{r}^{2}=0.79$. Each point correspond to the mean of $7-8$ plants \pm confidence intervals at $\mathrm{P}=0.05$.

\section{Genetic variability of isohydry results from variation in apparent stomatal sensitivity to soil water deficit}

Across the five cultivars studied, a continuum between isohydric (Ekigaïna) and anisohydric (Syrah) behavior has been clearly identified (see Figure 3). The stomatal behavior observed in Syrah and Grenache was consistent with previous report (Schultz, 1996, 2003; Soar et al., 2006). Our results showed that this gradient in isohydry is directly linked to variations in the degree of sensitivity of stomatal aperture in response to soil water deficit (see Figure 4). This difference in stomatal behavior was overall confirmed by the stomatal sensitivity factor $k$ from the BWB model, which takes into account the combined effects of climatic parameters and water stress on stomatal conductance (Ball et al., 1987). It is interesting to note that putative drought-sensitive cultivars (Mourvèdre and Ekigaiina) corresponded to the isohydric group as well as the putative drought-tolerant Grenache even if the latter was less extreme. By contrast, Syrah and Marselan could be classified as anisohydrics.

\section{A common stomatal sensitivity to soil water deficit and VPD?}

It is interesting to note that, for a given cultivar, a similar stomatal behavior was found in response to soil water stress and air water VPD, as previously suggested for several woody or herbaceous species (Franks et al., 2007) and grapevines (Schultz, 1996; Soar et al., 2006). In our study, Ekigaïna showed the strongest stomatal regulation in response to either decreasing $\psi_{\mathrm{PD}}$ levels or to increasing ambient VPD (see Figure 6). It must be pointed out that the VPD effects evaluated in this study were related to rapid changes, and thus results correspond to short-term responses with no long-term adaptation. However, previous results suggest that responses to rapid changes of VPD follow a similar pattern as long-terms responses to seasonal VPD evolution (Franks et al., 2007).
Although a relationship was found between responses to $\psi_{\mathrm{PD}}$ and VPD for a given cultivar, it remains unclear whether the mechanisms acting in response to soil water deficit and to VPD are the same. Tardieu and Davies (1992) proposed the ABA xylem sap as an integrator of edaphic and climatic effects on the stomata. VPD may alter the transport rate of root-sourced ABA to the guard cells (Bunce, 1996; Tardieu and Simonneau, 1998) or enhance stomatal sensitivity to the ABA signal (Tardieu and Davies, 1992).

\section{Consequences on assimilation and transpiration efficiency}

Progressive water stress leads to stomatal closure, simultaneously reducing transpiration and photosynthesis. For all cultivars studied, the reduction of $\mathrm{Pn}_{\max }$ in response to increasing soil water deficit occurs later than in $\mathrm{gs}_{\max }$, according to the literature (Cifre $e t$ al., 2005; Chaves et al., 2003). On average, for all cultivars, when $\psi_{\mathrm{PD}}$ decreased from -0.2 MPa to - $0.4 \mathrm{MPa}$, reductions in $\mathrm{Pn}_{\max }$ and $\mathrm{gs}_{\max }$ were approximately $17 \%$ and $40 \%$, respectively, which led to an increase in $\mathrm{WUE}_{\mathrm{i}}$ until $\psi_{\mathrm{PD}}$ reached approximately $-0.6 \mathrm{MPa}$ (see Figure 4 ). Afterward, a decrease of $W^{-} E_{j}$ was observed for all varieties, suggesting that the development of mesophyll limitations inhibits assimilation, exceeding the impact of further reduction in stomatal conductance to water vapor. Isohydric cultivars are expected to present a higher WUE than anisohydric cultivars under water deficit conditions (Schultz, 1996). However, the results reported here did not show significant differences between cultivars, except for Ekigaïna which presented a higher initial increase in $\mathrm{WUE}_{\mathrm{i}}$ up to $-0.5 \mathrm{MPa}$ of $\psi_{\mathrm{PD}}$. Thereafter (from -0.6 MPa), Ekigaïna showed a steeper reduction in $\mathrm{WUE}_{\mathrm{i}}$. It is interesting to note that severe water stress occasioned a reduction in $\mathrm{WUE}_{\mathrm{i}}$ in all cultivars, which shows the importance of avoiding extreme drought periods through crop and soil management (Parry et al., 2005). 


\section{Implications of diversity in water use strategies in grapevine cultivars on agronomic issues}

Even if isohydric behavior could be considered in a first approach as an efficient ecological adaptation to drought by limiting water loss, the ability of this category of cultivars to achieve complete maturity for commercial purposes is known to be impaired in situations of severe soil water deficit (Schultz, 1996; 2000). Moreover, both stomatal closure and early leaf senescence to prevent desiccation (as observed in Ekigaïna, Mourvèdre, and, to a lesser extent in Grenache) cause photosynthesis carbon uptake to decrease to near zero during a significant part of the vegetative cycle and may lead to a status of « carbon starvation ». This hypothesis is supported by several field observations under situations of severe soil water deficit, which revealed an incomplete maturation in Grenache and a strong reduction of fertility in Mourvèdre and Ekigaïna (author's personal observations).

In contrast, anisohydric cultivars, which maintained gas exchange at a lower soil water status, generally achieved complete maturation in situations of severe water restriction (Syrah, Marselan). However, the closer the anisohydric cultivar is to its cavitation threshold increases the risk of hydraulic failure if drought intensity continues.

Plant mortality has occasionally been observed in Syrah plantations, which are prone to severe drought in the Southern France, but the causal connection with hydraulic failure has not yet been established. Nevertheless, the progressive increase in dryness during the last few years puts the sustainability of these vineyards at risk.

\section{CONCLUSION}

This paper provides new information about physiological responses to water stress in some genotypes never studied before. The leaf gas exchange patterns observed here indicate large variations in adaptation to drought among grapevine cultivars. Genotypic variability in response to soil water deficit and VPD was directly linked to variations in the degree of sensitivity of stomatal aperture. A relation between stomatal responses to soil and air water deficit was found in each cultivar. A gradient from the most sensitive to the least sensitive variety has been observed. The most sensitive variety was Ekigaïna, characterised by a nearly constant midday leaf water potential, higher stomatal sensitivity (measured through gs and $k$ factor), and early leaf abscission (reduction of $\varepsilon i)$. In contrast, the least sensitive variety was Syrah which was characterised by a lower stomatal sensitivity consequently allowing midday leaf water potential to decline with drought. Mourvèdre and Grenache were closer to Ekigaïna while Marselan behaved similarly to Syrah.

Isohydric vs anisohydric regulation of water status is a critical factor in grapevine adaptation to drought. In dry and hot environments, extreme isohydric behavior, as observed for the first time in our study, dramatically reduces the capacities of carbon acquisition both at the leaf and whole-plant scales, affecting grape composition and production yield as often observed. On the other hand, anisohydric behavior as noted in Syrah allows the grape to reach maturity during drought, although it increases the likelihood of mortality via hydraulic failure. However, such hydraulic accident seems very uncommon. The influence of specific-cultivar response to water deficit on production yield and berry characteristics will be analysed in another paper for the same genotypes.

Overall, these results suggest that isohydry is not the only drought adaptation strategy for grapevines and that the success of viticulture under dry and hot conditions will depend on the identification and breeding of cultivars with drought tolerance traits.

Acknowledgements: JA. Prieto received funding from INTA (Argentina) during the experiment. The authors are grateful to Sara Maldonado, Ivette Sibille, Lorena Corbacho and Jean-Noël Lacapère for their help in data collection in the field.

\section{REFERENCES}

ALBUQUERQUE-REGINA M., 1993. Réponse des cépages de Vitis vinifera L. aux variations de l'environnement: Effets de la contrainte hydrique sur la photosynthèse, la photorespiration et la teneur en acide abscissique des feuilles. Thèse de doctorat, Université de Bordeaux II, 212 pp. France.

BALL J.T., WOODROW I. and BERRY J., 1987. A model predicting stomatal conductance and its contribution to the control of photosynthesis under different environmental conditions. In Progress in Photosynthesis Research (J. Biggins, ed.). pp. 221-224 Martinus Nijhoff, Dordrecht.

BOTA J., FLEXAS, J. and MEDRANO, H., 2001. Genetic variability of photosynthesis and water use in Balearic grapevine cultivars. Ann. Appl. Biol. 138, 353-361.

BUCKLEY T., 2005. The control of stomata by water balance. New Phytol. 168, 275-292.

BUNCE J.A., 1996. Does transpiration control stomatal responses to water vapour pressure deficit? Plant Cell Environ. 19,131135 .

CARBONNEAU A., 1980. Recherche sur les systèmes de conduite de la vigne: essai de maîtrise du microclimat et de la plante entière pour produire économiquement du raisin de qualité. Thèse de Doctorat, Université de Bordeaux II, 240 pp. France.

CHAVES M.M., HARLEY P.C., TENHUNEN J.D. and LANGE O. L., 1987. Gas exchange studies in two Portuguese grapevine cultivars. Physiol. Plant. 70, 639-647. 
CHAVES M.M., MAROCO J. and PEREIRA J., 2003. Understanding plant responses to drought from genes to the whole plant. Funct. Plant Biol. 30, 239-264.

CHAVES M.M., SANTOS T., SOUZA C., ORTUÑO M., RODRIGUES M., LOPES C., MAROCO J. and PEREIRA J., 2007. Deficit irrigation in grapevine improves water-use efficiency while controlling vigour and production quality. Ann. Appl Biol. 150, 237-252.

CIFRE J., BOTA J., ESCALONA J.M, MEDRANO H. and FLEXAS J., 2005. Physiological tools for irrigation scheduling in grapevine (Vitis vinifera $\mathrm{L}$ ). An open gate to improve water-use efficiency? Agri. Ecosyst. Environ. 106, 159-170.

CONDON A., RICHARDS R., REBETZKE G. and FARQUHAR G., 2004. Breeding for high water-use efficiency. J. Exp. Bot. 55, 2447-2460.

COOMBE B.G., 1995. Adoption of a system for identifying grapevine growth stages. Aust. J. Grape Wine Res. 1, 100110.

DAVIES W.J. and ZHANG J., 1991. Root signals and the regulation of growth and development of plants in drying soil. Annu. Rev. Plant Physiol., Plant Mol. Biol. 42, 55-76.

DAVIES W.J., WILKINSON S. and LOVEYS B.R., 2002. Stomatal control by chemical signalling and the exploitation of this mechanism to increase water use efficiency in agriculture. New Phytol. 153, 449-460.

FAO-UNESCO, 1981. Soil map of the world - 1/5.000.000. Food and Agriculture Organization, Rome.

FRANKS P., DRAKE P. and FROEND R., 2007. Anisohydric but isohydrodynamic: seasonally constant plant water potential gradient explained by a stomatal control mechanism incorporating variable plant hydraulic conductance. Plant Cell Environ. 30, 19-30.

GOMEZ del CAMPO M., RUIZ C. and LISSARRAGUE J.R., 2002. Effect of water stress on leaf area development, photosynthesis and productivity in Chardonnay and Airen grapevines. Am. J. Enol. Vitic. 53, 138-143.

HAMDY A., RAGAB R., SCARASCIA-MUGNOZZA E., 2003. Coping with water scarcity: water saving and increasing water productivity. Irrig. Drain. 52, 3-20.

JONES H., 1998. Stomatal control of photosynthesis and transpiration. J. Exp. Bot. 49, 387-398.

KOUNDOURAS S., VAN LEEUWEN C., SEGUIN G. and GLORIES Y., 1999. Influence de l'alimentation en eau sur la croissance de la vigne, la maturation des raisins et les caractéristiques des vins en zone méditerranéenne (Exemple de Némée, Grèce, cépage Saint-Georges, 1997). J. Int. Sci. Vigne Vin 33, 149-160.

LEBON E., PELLEGRINO A., LOUARN G. and LECOEUR J., 2006. Branch development controls leaf area dynamics in grapevine (Vitis vinifera) growing in drying soil. Ann. Bot. 98, 175-185.

LOUARN G., CHEZE C., JACQUET O., BOUTIN F., LECOEUR J. and LEBON E., 2005. Estimation of light interception efficiency of a vineyard with hemispherical photographs. Proceedings of the XIVth International GESCO Congress, Geisenheim, Germany pp. 231- 235.
McCARTHY M., 1997. The effect of transient water deficit on berry development of cv. Shiraz (Vitis vinifera L.). Aust.J. Grape Wine Res. 3, 102-108.

McCARTHY M., 2000. Developmental variation in sensitivity of Vitis vinifera L. (Shiraz) berries to soil water deficit. Aust. J. Grape Wine Res. 6, 136-140.

MEDRANO H., ESCALONA J.M., CIFRE J., BOTA J. and FLEXAS J., 2003. A 10-year study on the physiology of two Spanish grapevine cultivars under field conditions: effects of water availability from leaf photosynthesis to grape yield and quality. Funct. Plant Biol. 30, 607-619.

MOTT K. and PARKHURST D., 1991. Stomatal responses to humidity in air and helox. Plant Cell Environ. 14, 509-515.

MOTT K. and FRANKS P., 2001. The role of epidermal turgor in stomatal interactions following a local perturbation in humidity. Plant Cell Environ. 24, 657-662.

OJEDA H., DELOIRE A. and CARBONNEAU A., 2001. Influence of water stress deficits on grape berry growth. Vitis 40, 141-145.

OJEDA H., ANDARY C., KRAEVA E., CARBONNEAU A. and DELOIRE A., 2002. Influence of pre- and postveraison water deficit on synthesis and concentration of skin phenolic compounds during berry growth of Vitis vinifera cv. Shiraz. Am. J. Enol. Vitic. 53, 261-267.

PARRY M., FLEXAS J. and MEDRANO H., 2005. Prospects for crop production under drought: research priorities and future directions. Ann. Appl. Biol. 147, 211-226.

SCHULTZH., 1996. Water relations and photosynthetic responses of two grapevine cultivars of different geographical origin during water stress. Acta Hortic. 427, 251-266.

SCHULTZ H., 2000. Physiological mechanisms of water use efficiency in grapevines under drought conditions. Acta Hortic. 526, 115-136.

SCHULTZ H., 2003. Differences in hydraulic architecture account for near-isohydric and anisohydric behaviour of two filedgrown Vitis vinifera L. cultivars during drought. Plant Cell Environ. 26, 1393-1405.

SCHULTZH., LEBON E. and ROUSSEAU C., 1999. Suitability of the «Ball, Woodrow, Berry » model for the description of stomatal coupling to photosynthesis of different Vitis species and Vitis vinifera cultivars in different climatic regions at various levels of water deficit. Acta Hortic. 493, 17-30.

SOAR C., SPEIRS J., MAFFEI S., PENROSE A., McCARTHY M. and LOVEYS B., 2006. Grapevine varieties Shiraz and Grenache differ in their stomatal response to VPD: apparent links with ABA physiology and gene expression in leaf tissue. Aust. J. Grape Wine Res. 12, 2-12.

TARDIEU F. and DAVIES W.J., 1992. Stomatal response to abscisic acid is a function of current plant water status. Plant Physiol. 98, 540-545.

TARDIEU F. and SIMONNEAU T., 1998. Variability among species of stomatal control under fluctuating soil water status and evaporative demand: modelling isohydric and anisohydric behaviours. J. Exp. Bot. 49, 419-432. 
TONIETTO J. and CARBONNEAU A., 2004. A multicriterion climatic classification system for grape-growing regions worldwide. Agric. For. Meteorol. 124, 81-97.

VAN LEEUWEN K., TREOGAT O., CHONÉ X., JAECK M.E., RABUSSEAU S. and GAUDILLÈRE J.P., 2003. Le suivi du régime hydrique de la vigne et son incidence sur la maturation du raisin. Bull. O.I.V. 76, 367-378.

WINKEL T. and RAMBAL S., 1990. Stomatal conductance of some grapevines growing in the field under Mediterranean environment. Agric. For. Meteorol. 51, 107-121. 